\title{
MRS Increases Communication with U.S. Policy Makers
}

Advances in materials have contributed much to the quality of life we enjoy, and will continue to be important for the foreseeable future. Nevertheless, we as materials scientists and engineers have done an inadequate job of educating U.S. policy makers in Washington about what "materials research" is, much less what it has accomplished. With the end of the Cold War, hard questions are being asked about federal funding for science and engineering, a part of the federal budget that had come to be viewed as more or less an entitlement for several decades. Such questions are likely to become increasingly pointed as the new Congress begins work on the 1996 budget. Consequently, many programs of importance to the materials research community are in jeopardy, and no one will come to the defense of materials research if the practicing scientists and engineers fail to speak up.

Since 1990, the Materials Research Society has been seeking to "enhance the environment in the United States for conducting materials research, and effectively integrating this research into technologies for the benefit of society." With the help of Elton Kaufmann, the MRS Office of Public Affairs was opened in Washington, D.C. in 1990, in part "to provide a larger and more unified voice for materials-related issues." The MRS Public Affairs Committee, chaired by Tom Picraux, responds to and initiates opportunities for MRS to interact with government officials and public and private organizations on matters of science and technology policy, and participates in or plans events related to that policy. The Committee also aids the MRS Executive Committee in identifying policy issues relevant to the Society's interests and drafting proposed responses, with supporting background material, for Executive Committee and Council consideration and disposition.

In recent years, the public affairs activities of MRS have been limited primarily to two areas: informing members about actions in Washington and providing information on materials-related issues to policy makers. MRS meeting attendees have had the opportunity to attend special forums and panels on materials policy developments. Dialogue with government officials has occurred as officers of the Society have on occasion responded to

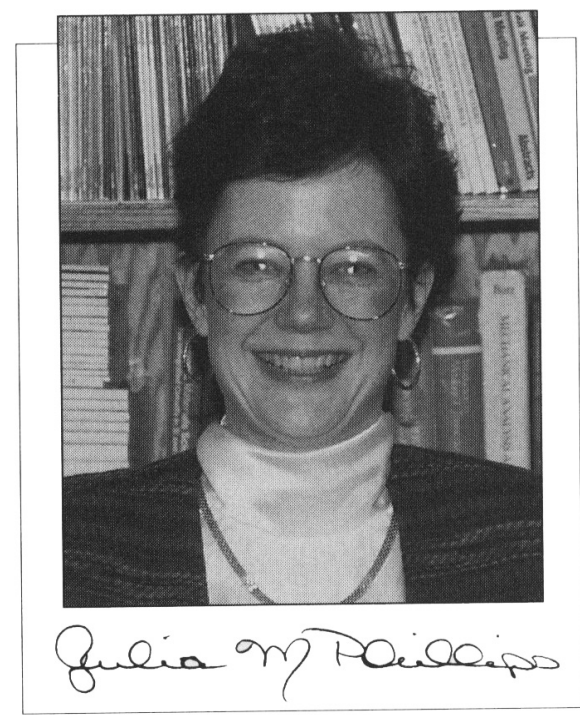

significant developments or visited government officials such as the director of the National Science Foundation and associate directors in the Office of Science and Technology Policy (OSTP) to emphasize issues important to the materials research community. Last summer, when Congress threatened to cut over $\$ 900 \mathrm{mil}$ lion from university research funding by the Department of Defense, officers of the Society reacted quickly, as did many other technical societies and concerned organizations such as universities, to voice their concerns to members of Congress. Much of the cut was restored in conference.

In light of the challenges facing the materials research community, the Public Affairs Committee has recently increased its level of activity. The committee met in Washington on January 13 to chart its direction for the year. The group established the overall goals of educating policy makers about the importance of materials research and informing the MRS membership about the impact of policy issues on materials research. Following are the specific actions to be taken.

Officers of the Society are best able to communicate with policy makers when well-informed about the constituency that they represent. Consequently, the Public Affairs Committee is working closely with the Membership Committee in the member needs assessment discussed in my last letter [see MRS Bulletin, March 1995, p. 4] so that important demographic information such as sector of employment and field of highest degree can be collected.

Policy makers increasingly use the Internet. This provides an opportunity to make use of the MRS homepage to educate these individuals (as well as other interested individuals) about the impact of materials research on our lives. Members of the Public Affairs Committee are identifying a number of specific examples of such success stories for posting on the homepage.

During the early 1990s we were able to identify the major places in the federal budget that supported materials, thanks to the Advanced Materials and Processing Program (AMPP) initiative coordinated by OSTP. This is no longer the case; the compilation of such current information is unavailable to the public. Over the next year, MRS will encourage OSTP to generate such a materials budget assessment. The Society will also try to team with other societies to work toward this goal.

Finally, and equally important, is the goal of informing MRS members about the effects of policy matters. This month a new department debuts in the MRS Bulletin. Entitled Public Affairs Forum (see p. 17 in this issue), the aim is not only to report on news items concerning materials policy but also to explain the potential impact on the lives of MRS members.

The days during which scientists and engineers could practice their trade in isolation from the vagaries of national politics are over, if they ever really existed. This realization is striking increasing numbers of materials scientists, but many are unsure how to respond to this reality. MRS has made strides to become involved in the policy arena in a responsible way over the past few years, but still has far to go. In the end, the leadership can do only what you, the members, endorse. Let us hear from you!

Julia M. PhilliIs

Julia M. Phillips

Thin Film Research Group

Room 1D-151

600 Mountain Avenue

Murray Hill, NJ 07974

Phone: (908) 582-4428

Fax: (908) 582-2521

E-mail: jmp@allwise.att.com 